\title{
MALIGNANT MENINGIOMA WITH EXTRACRANIAL METASTASES
}

\author{
Eduardo Simões Estanislau', Gervásio Teles Cardoso de Carvalho², \\ Baltazar Leão Reis', Warley de Freitas Barbosa', Rafael Augusto Castro Santiago Brandão', \\ Atos Alves de Sousa $a^{2}$, João Batista de Oliveira ${ }^{3}$
}

Meningiomas are tumors originating from meningothelial cells of the arachnoid membrane and are benign in most cases $^{1-3}$, corresponding to about $15 \%$ to $18 \%$ of all primary tumors of the central nervous system (CNS) ${ }^{3,4}$. Extracranial metastases of meningiomas are rare and occur in less than 1 per 1000 cases $^{3-5}$. According to the WHO criteria, the histological grade of the tumor is the most important predictive factor of malignancy ${ }^{6}$. Anaplastic meningioma histologically corresponds to $\mathrm{WHO}$ grade III and shows overt signs of malignancy accompanied by a high rate of mitosis and abundant necrosis. In addition, this form is characterized by intense cerebral invasion'. The exact definition of malignant or anaplastic meningioma is still a matter of discussion. One factor that undoubtedly defines malignant meningioma is the occurrence of extraneural metastases. However, according to some investigators, the occurrence of distant metastases is not an unequivocal sign of histological malignancy.

We report a case of a 75-year-old man with malignant meningioma who presented extracranial metastases.

\section{CASE}

A 75-year-old man was submitted to total resection of a right temporoparietal meningioma in October 2000 (Fig 1). Anatomopathological examination revealed an atypical meningioma (grade II). In March 2002, tumor recurrence at the surgical site with invasion of bone and subcutaneous tissue was diagnosed. A new total resection of the tumor, followed by cranioplasty, was performed. The patient was referred for radiotherapy. Postoperative magnetic resonance imaging (MRI) showed total resection of the tumor, in addition to another small nodular lesion in the left temporal lobe also suggestive of a meningioma, which has been present since the first exam and had not increased in size.

In January 2006, a MRI was performed after a seizure which showed signs of tumor recurrence in the right frontoparietal

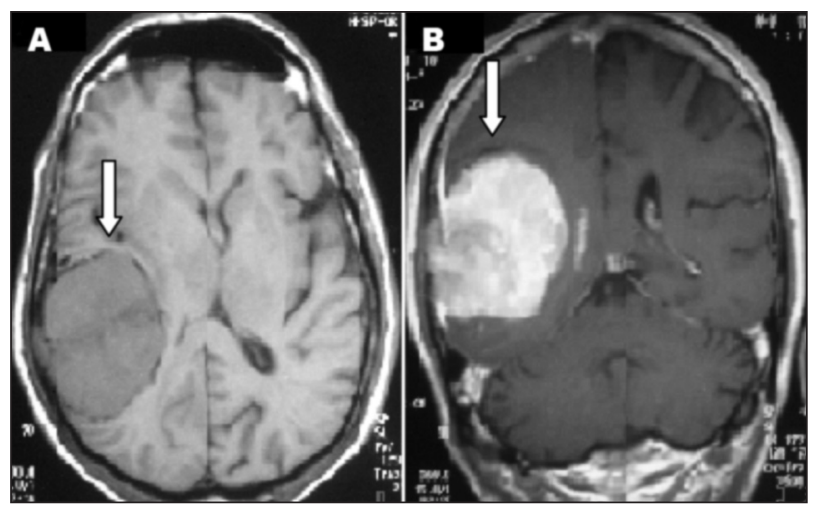

Fig 1. [A] Axial T7-weighted MRI of the brain showing a homogenous hypointense lesion with defined limits in the right temporoparietal lobe. [B] Coronal T7-weighted section after gadolinium administration showing intense and homogenous contrast enhancement.

region and a small right parietooccipital lesion and the lesion in the left temporal lobe whose aspect remained unchanged. The choice was to clinically follow up the patient, when a hard (stony) nodule was subsequently identified in the right neck region. A chest computed tomography (CT) was performed, which showed a nodular lesion in the lower lobe of the right lung (Fig 2). A needle aspiration biopsy of the cervical lesion revealed an "unclassified neoplasm of epithelial or myoepithelial lineage". Immunohistochemical analysis of the material confirmed the diagnosis of metastatic meningioma.

Chemotherapy with hydroxyurea was initiated in March 2006. Growth of the cervical lesion was observed and the patient presented four additional brain lesions showing the same characteristics as the previous ones. The chemotherapy regimen was changed and interferon was introduced.

In October 2006, the patient was submitted to right radical neck dissection, with the diagnosis of anaplastic meningioma being confirmed after immunohistochemistry.

\section{MENINGIOMA MALIGNO COM METÁSTASES EXTRACRANIANAS}

'Resident, Neurosurgery Service, Santa Casa de Belo Horizonte, MG, Brazil; ${ }^{2}$ Assistant, Neurosurgery Service, Santa Casa de Belo Horizonte and Faculdade de Ciências Médicas, Belo Horizonte MG, Brazil; ${ }^{3}$ Assistant, Head and Neck Surgery Service, Santa Casa de Belo Horizonte, Belo Horizonte MG, Brazil. 

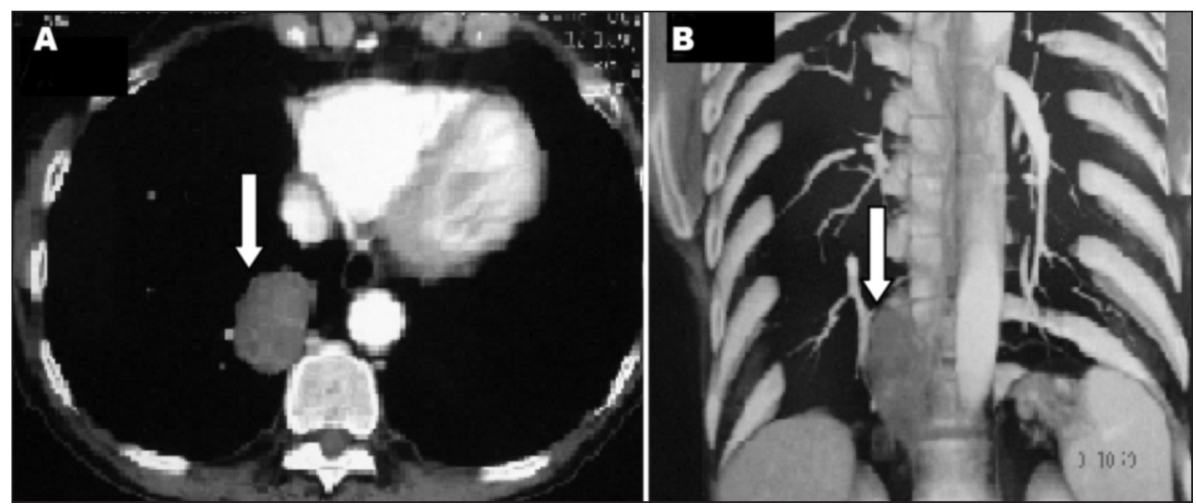

Fig 2. [A] Axial chest CT scan showing a hypodense, nodular, solid and homogenous lesion in the lower pole of the right lung adjacent to the vertebral body. [B] Chest $C T$ with coronal reconstruction showing a lesion in the lower lobe of the right lung in its more medial portion.

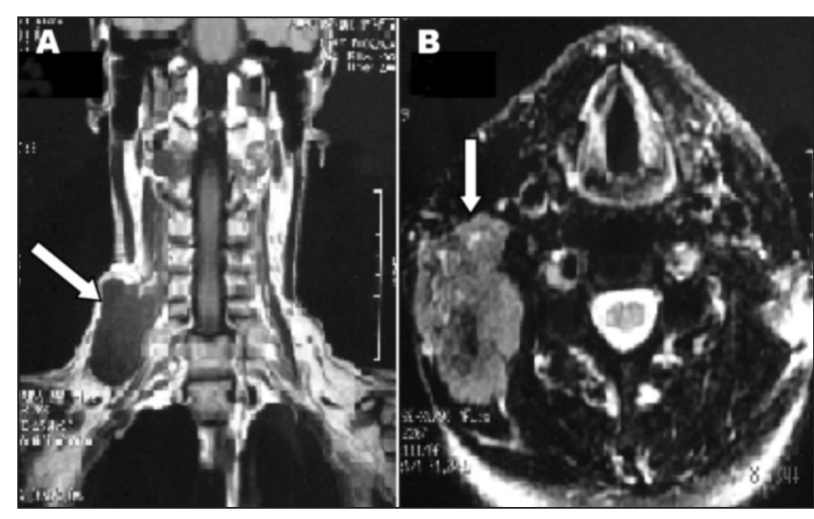

Fig 3. [A] Coronal T7-weighted MRI of the neck region showing a hypointense homogenous lesion. [B] Axial T2-weighted image of the right cervical lesion showing a more hypointense center suggestive of central necrosis

In November 2006, the right and left temporal lesions were treated by stereotaxic radiosurgery. Until January 2008, there was no growth of these lesions.

Thoracotomy associated with segmentectomy of the lower lobe of the right lung was performed in December 2006. The diagnosis of metastasis of a malignant meningioma was also confirmed.

In April 2007, a MRI of the neck region showed cervical mass invading the right pulmonary apex (Fig 3). Lesions were also observed in the second thoracic vertebra and in the region of the right jugular foramen. Conservative treatment was chosen because of the depth of the lesions. A chest CT revealed a solid recurrent lesion in the medial portion of the lower third of the right lung and a mass adjacent to the right adrenal gland (Fig 2).

Chemotherapy failed and a new regimen consisting of ifosfamide, carboplatin and etoposide was initiated, whose outcome was also unsatisfactory. Thus, radiotherapy of the cervical lesions was chosen. The patient developed two additional metastases in the subcutaneous tissue of the posterior wall of the right hemithorax.

In July 2008 he underwent radical resection surgery of the recurrent cervical metastasis and died about 30 days later due to surgery complications.

\section{DISCUSSION}

Although most of meningiomas are histologically benign, some may invade the venous sinuses, bones, soft tissues of the scalp, paranasal sinuses and even the brain. Even after total resection, local recurrence has been observed in 9 to $32 \%$ of cases ${ }^{4}$.

The prevalence of malignant histology of meningiomas ranges from 2 to $10 \%$. The prevalence of metastases is $0.76 \%$ when all meningiomas are considered and about $43 \%$ when only malignant meningiomas are considered.

Simpson ${ }^{9}$ observed histological infiltration of the dural sinuses in $14 \%$ of cases of meningiomas in general, but in only one case this was associated with detectable extracranial metastases. Kepes ${ }^{10}$ suggests that many meningiomas recur at least once before presenting distant metastases.

The most common sites of metastases of meningiomas are the lungs $(60 \%)$, followed by the abdomen and liver (34\%), cervical lymph nodes (18\%), long bones, pelvis and skull (11\%), pleura ( $9 \%)$, vertebrae $(7 \%)$, CNS $(7 \%)$, and mediastinum $(5 \%)^{10}$. The kidneys, bladder, thyroid, breasts, thymus, heart, skin, vulva, adrenal glands and eyes are only occasionally affected ${ }^{10}$. The present patient presented metastases both at more common sites such as the lung and cervical lymph nodes and at rare sites such as the adrenal glands and skin.

The histological grade of the tumor is the most important predictive factor of recurrence or metastases ${ }^{3,6,11}$. A review of the histological descriptions of metastatic meningiomas showed that these tumors are predominantly of the papillary, atypical and malignant subtypes ${ }^{3}$. However, a high cell proliferation rate is not essential for the occurrence of extracranial metastases and any histologically benign meningioma can possibly metastasize $\mathrm{e}^{3,7}$.

Meningiomas frequently present multiple histologi- 
cal variants within a single tumor ${ }^{4}$. Histological evaluation of the lesion using a grading system that comprises mitotic figures, hypercellularity, nuclear pleomorphism and areas of necrosis helps predict recurrence or potential metastases ${ }^{3,4}$. Immunohistochemical analysis of a nuclear protein related to cell proliferation, $\mathrm{Ki}-67$, is also useful to evaluate tumor agressiveness ${ }^{3,4}$. Tumors that are positive for $\mathrm{Ki}-67$ tend to be more aggressive, with a higher chance of recurrence and/or metastases ${ }^{4}$.

The treatment of choice for primary intracranial or intraspinal meningiomas is total surgical resection ${ }^{4}$. Postoperative radiotherapy has been recommended for the prevention of local recurrence, especially in the case of subtotal resection or histology suggestive of malignancy. The efficacy of chemotherapy for intracranial meningiomas is known to be low, as observed in the present case. No therapeutic regimen has been established for metastatic meningiomas ${ }^{12}$. In addition, the role of radiotherapy still needs to be clearly defined.

In conclusion, although uncommon, extracranial metastases of meningiomas should always be included in the differential diagnosis of patients with a history of meningioma who developed lesions suggestive of distant metastases, especially patients who underwent surgery and presented tumor recurrence, as was the case here.

\section{REFERENCES}

1. Kleihues P, Burguer PC, Scheithauer BW in collaboration with L.H. Sobin and Pathologists in 14 Countries. Histological typing of tumours of the central nervous system, $2^{\text {nd }}$ Ed. Berlin: Springer- Verlag, 1993:37-42.

2. Louis DN, Ohgaki H, Wiestler OD, et al. The 2007 WHO classification of tumours of the central nervous system. Acta Neuropathol 2007;114: 97-109.

3. Erman T, Hanta I, Haciyakupoglu S, Zorludemir S, Zeren H, Göçer A. Huge bilateral pulmonary and pleural metastasis from intracranial meningioma: a case report and review of the literature. J Neurooncol 2005;74:179-181.

4. Teague SD, Conces Jr DJ. Metastatic meningioma to the lungs. J Thorac Imaging 2005;20:58-60.

5. Vik A, Kvikstad A, Unsgard G, Jorgensen JV, Torp SH. A 54-year-old man with a large subcutaneous skull erosion and focal epileptic seizures. Tidsskr Nor Laegeforen 2006;126:2386-2387.

6. Fabi A, Nuzzo C, Vidlri A, et al. Bone and lung metastasis from intracranial meningioma. Anticancer Res 2006;26:3835-3837.

7. Souza HL, Caldas JR, Menguita LG, et al. Metástase de meningioma para linfonodos cervicais: relato de caso e revisão da literatura. Arq Bras Neurocir 2000;19:28-31

8. Rondinelli PIP, Viana CR, Osorio CAM, Sredni ST. Extenso meningioma atípico na infância: relato de caso. Arq Neuropsiquiatr 2003;61:695-698.

9. Simpson D. The recurrence of intracranial meningiomas after surgical treatment. J Neurol Neurosurg Psychiatry 1957;20:22-39.

10. Kepes JJ. Meningiomas: biology, pathology, and differential diagnosis. Masson Monographs in Diagnostic Pathology, vol. 4. New York, Masson, 1982:190-200

11. Pramesh CS, Saklani AP, Pantvaidya GH, et al. Benign metastasizing meningioma. Jpn J Clin Oncol 2003;33:86-88.

12. Le May DR, Bucci MN, Farhat SM. Malignant transformation of recurrent meningioma with pulmonary metastasis. Surg Neurol 1989; 31: 365-368. 